\title{
Reflectance Spectroscopy Characteristics of Turquoise
}

\author{
Jun-Ting Qiu ${ }^{1,2, *}$, Hui $\mathrm{Qi}^{3}$ and Ji-Lin Duan ${ }^{1}$ \\ 1 School of Earth Sciences and Resources, China University of Geosciences, Beijing 100083, China; \\ duanjilin@cugb.edu.cn \\ 2 National Key Laboratary of Science and Technology on Remote Sensing Information and Image Analysis, \\ Beijing 100029, China \\ 3 School of Gemmology, China University of Geosciences, Beijing 100083, China; qihui@cugb.edu.cn \\ * Correspondence: qiujunting@cugb.edu.cn or midimyself@126.com; Tel.: +86-10-6496-4688
}

Academic Editors: David Phillips and David Chew

Received: 18 June 2016; Accepted: 21 December 2016; Published: 30 December 2016

\begin{abstract}
In this study, we determined the reflectance spectra of four types of turquoise with different hardness (porcelain, hard turquoise, soft turquoise, and loose turquoise) using an ASD ${ }^{\mathrm{TM}}$ TerraSpec spectrometer (spectral range 350-2500 nm, Visible-Near Infrared, and Short-wave Infrared). Several absorption features, including six narrow absorption peaks at $425 \mathrm{~nm}, 1480 \mathrm{~nm}, 2160 \mathrm{~nm}$, $2218 \mathrm{~nm}, 2253 \mathrm{~nm}$, and $2347 \mathrm{~nm}$, and three wide peaks between 625-756 nm, 756-915 nm, and 1885-2133 $\mathrm{nm}$ have been identified. The strength of the absorption of turquoise increased with decreasing hardness. The absorption peaks at $2160 \mathrm{~nm}, 2218 \mathrm{~nm}, 2253 \mathrm{~nm}, 2347 \mathrm{~nm}$, and 1885-2133 nm on some turquoise spectra (porcelain spectra, for example) were relatively weak, while those at $425 \mathrm{~nm}, 1480 \mathrm{~nm}, 625-756 \mathrm{~nm}$, and 756-915 nm were always observed on all turquoise spectra, which could be the diagnostic absorption features for turquoise. Additionally, the hyper-spectral imaging (spectral range 1000-2500 nm, Short-wave Infrared) of the four types of turquoise were obtained using a HySpex ${ }^{\mathrm{TM}}$ imager. The Spectral Angle Mapper (SAM) method was successfully used to recognize turquoises, suggesting that hyper-spectral imaging may serve as a useful tool for fast turquoise identification and separation, especially for massive turquoise samples.
\end{abstract}

Keywords: reflectance spectroscopy; hyper-spectral imaging; turquoise; identification and separation

\section{Introduction}

Materials with different surface features can reflect the sun's radiation. The reflectance property depends on the physical and chemical states of the material, and can be visualized in the form of spectral reflectance curves (or reflectance spectra) as a function of wavelength. Differences in reflectance spectra can be used to classify or distinguish different materials [1-7]. The development of Hyper-spectral imaging (or imaging spectroscopy) integrates the power of digital imaging and spectroscopy. Every pixel in the image contains a continuous spectrum, and can be used to characterize the materials with great precision and detail.

Hyper-spectral imaging has been widely used in geological mapping [8-11], ore exploration [12-14], nature conservation [15-18], and food or drink quality analysis [19,20]. Recent studies have also used this technology to conveniently and economically examine ancient documents and archaeological artifacts [21-23]. Whether this technology can be used in gem identification and separation is not yet understood. Unfortunately, though many spectra of different gems have been reported by previous studies [24-28], most of them cannot be used in reflectance hyper-spectral imaging analysis.

Turquoise-hydrous phosphate of aluminum and copper, $\mathrm{Cu}\left(\mathrm{Al}, \mathrm{Fe}^{3+}\right)_{6}\left(\mathrm{PO}_{4}\right)_{4}(\mathrm{OH})_{8} \cdot 4 \mathrm{H}_{2} \mathrm{O}$-is of gemmological interest, with a brilliant history of several thousand years. It was deeply loved by the Chinese, and by people from various countries. As early as in ancient Egypt, ancient Mexico, 
and ancient Persia, turquoise was considered to be mysterious, and was used in talismans and burial objects. It was used by the Egyptians to carve gods to guard treasure. The Indians think that wearing a turquoise decoration can ward off evil spirits and get gods' blessings. In Tibet, it is used in ornaments-it was used for the first Tibetan king's crown, and as shrine offerings.

China is rich in gem-quality turquoise resources, including north-west Hubei Province. In this study, we determined the reflectance spectra $(350-2500 \mathrm{~nm})$ of four types of turquoise samples (porcelain, hard turquoise, soft turquoise, and loose turquoise) sourced from Shiyan city, Hubei province using an $\mathrm{ASD}^{\mathrm{TM}}$ TerraSpec spectrometer, and used a HySpex ${ }^{\mathrm{TM}}$ imager to obtain the hyper-spectral image (1000-2500 nm) of the turquoise samples, in an attempt to understand their spectral features and to evaluate the capability of hyper-spectral imaging in turquoise identification and separation.

\section{Materials and Methods}

\subsection{Samples}

The turquoise samples used in this study (Figure 1) are divided based on density and hardness. They are porcelain (high hardness and density), hard turquoise (medium hardness and density), soft turquoise (medium to low hardness and density), and loose turquoise (low hardness and density).

Porcelain is dark blue to dark green, has a delicate texture with Mohs hardness between 5.5 and 6 , and grain size ranging from 1 to $4 \mathrm{~mm}$.

Hard turquoise is blue-green to sea foam with relatively high density. The Mohs hardness of the sample is $4.5-5.5$, and the grain size is from 3 to $5 \mathrm{~mm}$.

Soft turquoise is light blue with relatively low density. The Mohs hardness is below 4.5 , and the grain size is from 5 to $6 \mathrm{~mm}$.

Loose turquoise is light grey and soft, with earthly luster and dull with grain size between 4 and $5 \mathrm{~mm}$. It marks paper in much the same way as graphite.
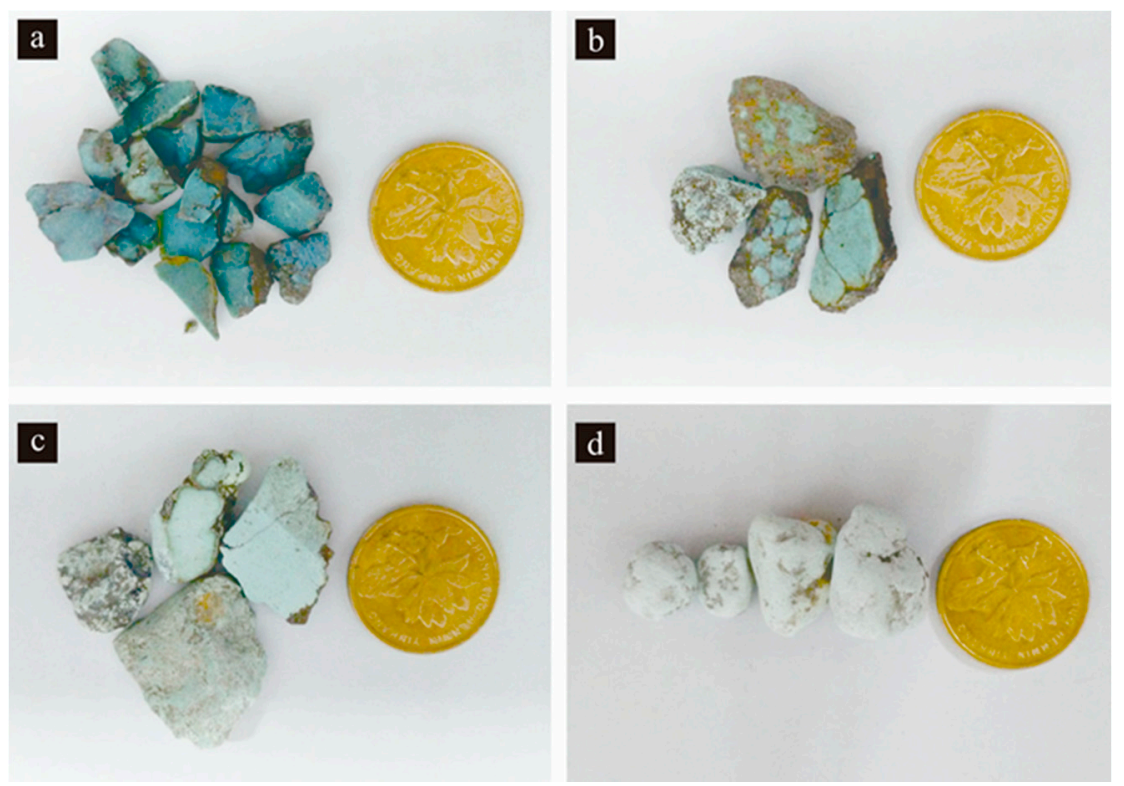

Figure 1. Photographs of four turquoise samples. (a) porcelain; (b) hard turquoise; (c) soft turquoise; (d) loose turquoise.

\subsection{Instruments}

Spectrum measurement experiments of four turquoise samples were carried out using an ASD ${ }^{\mathrm{TM}}$ TerraSpec spectrometer (Analytical Spectral Devices Inc., Boulder, CO, USA), for which the spectral 
range is $350-2500 \mathrm{~nm}$, and the spectral resolutions are $3 \mathrm{~nm}$ at $700 \mathrm{~nm}$ and $6 \mathrm{~nm}$ at $1400 \mathrm{~nm}$ and $2100 \mathrm{~nm}$. The sampling intervals for the instrument are $1.4 \mathrm{~nm}$ between $350 \mathrm{~nm}$ and $1000 \mathrm{~nm}$, and $2 \mathrm{~nm}$ between $1000 \mathrm{~nm}$ and $2500 \mathrm{~nm}$. The signal-to-noise values are $9500 \mathrm{DN}$ at $700 \mathrm{~nm}, 5000 \mathrm{DN}$ at $1400 \mathrm{~nm}$, and $800 \mathrm{DN}$ at $2100 \mathrm{~nm}$.

The hyper-spectral images of the turquoise samples were acquired using a HySpex ${ }^{\mathrm{TM}}$ hyper-spectral imager (HySpex ${ }^{\mathrm{TM}}$ SWIR-320m-e, NEO, Skedsmo, Norway). The spectral range of the instrument is from $1000 \mathrm{~nm}$ to $2500 \mathrm{~nm}$ at a spectral sampling interval of $6 \mathrm{~nm}$. The instrument can also provide images showing a textural map of minerals with a spatial resolution of $\sim 0.75 \mathrm{~mm}$. Detailed technical specifications of the HySpex ${ }^{\text {TM }}$ SWIR-320m-e imager are given in Table 1.

Table 1. Technical specification of HySpex ${ }^{\mathrm{TM}}$ SWIR-320m-e imager.

\begin{tabular}{cc}
\hline Item & Parameter \\
\hline Detector & $\mathrm{HgCdTe}(320 \times 256)$ \\
Spectral range & $1.0-2.5 \mu \mathrm{m}$ \\
Spatial pixels & 320 \\
FOV across track & $13.5^{\circ}$ \\
Pixel FOV across/along track & $0.75 \mathrm{mrad} /$ \\
Spectral sample & $0.75 \mathrm{mrad}$ \\
Number of bands & $6 \mathrm{~nm}$ \\
Digitization & 256 \\
Max frame rate & $14 \mathrm{bit}$ \\
Dimension (lwh in cm) & $100 \mathrm{fps}$ \\
Sensor head weight & $36 \times 14 \times 15.2$ \\
\hline
\end{tabular}

FOV: Angle of view; lwh: Length-width-height; Note: The data was sourced from [29].

\section{Experiments}

\subsection{Spectral Measurement}

The ASD ${ }^{\mathrm{TM}}$ spectrometer was set up following the guidelines described in the Labspec4 user manual. An accessory light source (halogen lamp) was employed to measure the spectrum without sunlight. The ASD ${ }^{\mathrm{TM}}$ instrument was connected to a laptop and manipulated using the RS3 software package (Analytical Spectral Devices Inc., Boulder, CO, USA). Before the experiment, a white reference was introduced to optimize and calibrate the instrument. The reflectance of the white reference was automatically set to 1 by the RS3 software. Since the turquoise samples are usually in small particles, a black plastic plate with a coarse surface was used to make turquoise particles flat. During the experiment, the detector was closed to the turquoise particle level.

Five spectra were recorded by the RS3 software in one measurement to monitor any variation during the measurement. After the experiment, a repeat measurement of the white reference was conducted to check whether a significant change of the standard spectrum occurred during the experiment. The spectra of four turquoise samples were exported using RS3 software, then saved as ASCII files with ViewSpecPro software (Analytical Spectral Devices Inc., Boulder, CO, USA). The ASCII files were converted to a spreadsheet file with Excel ${ }^{\mathrm{TM}}$ 2007, then plotted with CorelDRAW ${ }^{\mathrm{TM}} \mathrm{X}^{\text {. }}$. The name list of the spectral files and related turquoise samples are given in Table 2.

Table 2. Name list of spectral files and related turquoise samples.

\begin{tabular}{cc}
\hline File Name List & Turquoise Samples \\
\hline qjt-00061.asd.ref to qjt-00065.asd.ref & porcelain \\
qjt-00136.asd.ref to qjt-00140.asd.ref & hard turquoise \\
qjt-00151.asd.ref to qjt-00155.asd.ref & soft turquoise \\
qjt-00161.asd.ref to qjt-00165.asd.ref & loose turquoise \\
\hline
\end{tabular}




\subsection{Hyper-Spectral Image Scanning}

The HySpex ${ }^{\mathrm{TM}}$ imaging spectrometer was deployed onto a dynamical system (Figure 2) so that it could be controlled to move in a straight line. Two 150 Watt halogen lamps were also fixed onto the dynamical system to provide a light supply (Figure 2). The imaging spectrometer and the dynamical system were connected to a computer so that it could be manipulated using the HySpex ${ }^{\mathrm{TM}}$ Ground software (NEO, Skedsmo, Norway). Before scanning, the four types of turquoise samples were placed onto a paper plate, as shown in Figure 3. A white reference was also placed on the plate for further reflectance calibration (Figure 3). The raw DN image containing the four samples was recorded by the HySpex ${ }^{\mathrm{TM}}$ Ground software and converted to reflectance hyper-spectral image using an empirical method provided by the ENVI software (Exelis Inc., Tysons Corner, VA, USA).

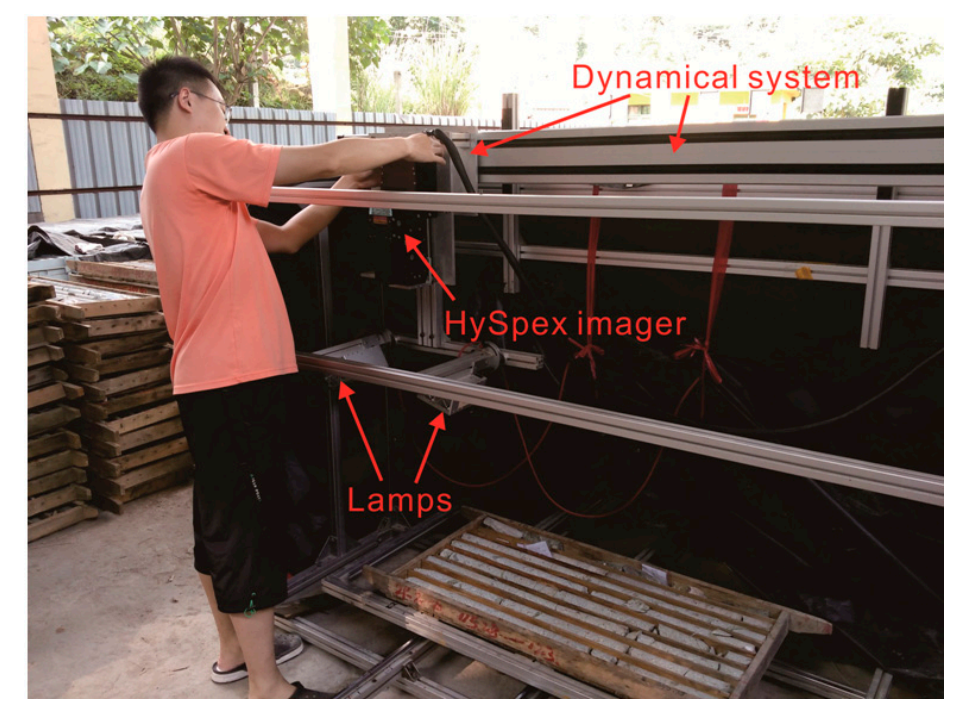

Figure 2. Deployment of HySpex ${ }^{\mathrm{TM}}$ imager.

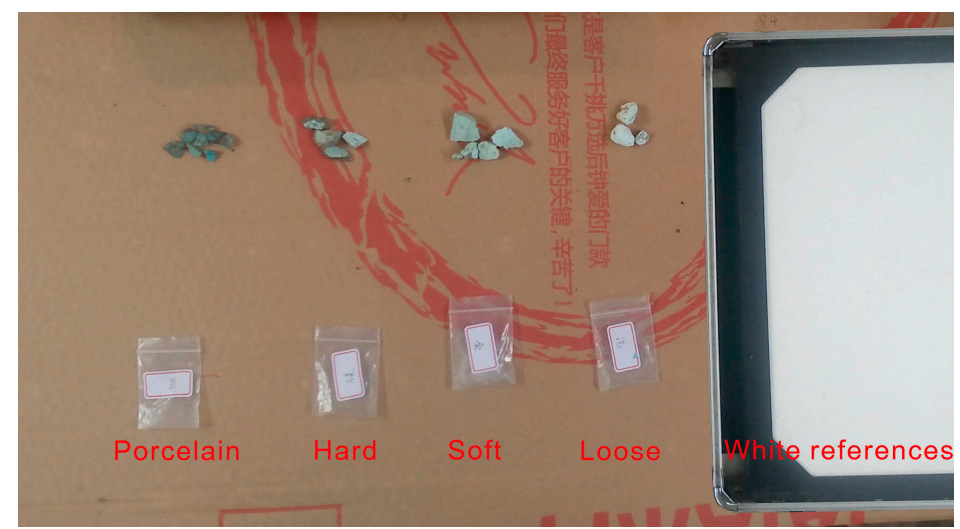

Figure 3. Deployment of four types of turquoise samples.

\section{Results}

\subsection{Spectra}

The spectral results measured by the $\mathrm{ASD}^{\mathrm{TM}}$ spectrometer are shown in Figure 4. As shown in Figure $4 \mathrm{a}$, the white reference has reflectance values equal to 1 . The black plastic plate has low reflectance values, generally below 0.025 . The reflectance spectrum of the black plastic plate is flat without any absorption feature. Such low reflectance values and the flat spectrum suggest that 
influence from the black plastic plate during spectral measurements of the turquoise samples can be neglected. The repeated measurement of the white reference after the experiment also showed reflectance values equal to 1 , suggesting that no significant change occurred during the experiment. In Figure 4a, it is also noted that the spectra of the white reference have large signal noise between $350 \mathrm{~nm}$ and $390 \mathrm{~nm}$ and between $2400 \mathrm{~nm}$ and $2500 \mathrm{~nm}$. This signal noise in the above two wavelength intervals may be mistaken for absorption features, and should be treated with great caution.
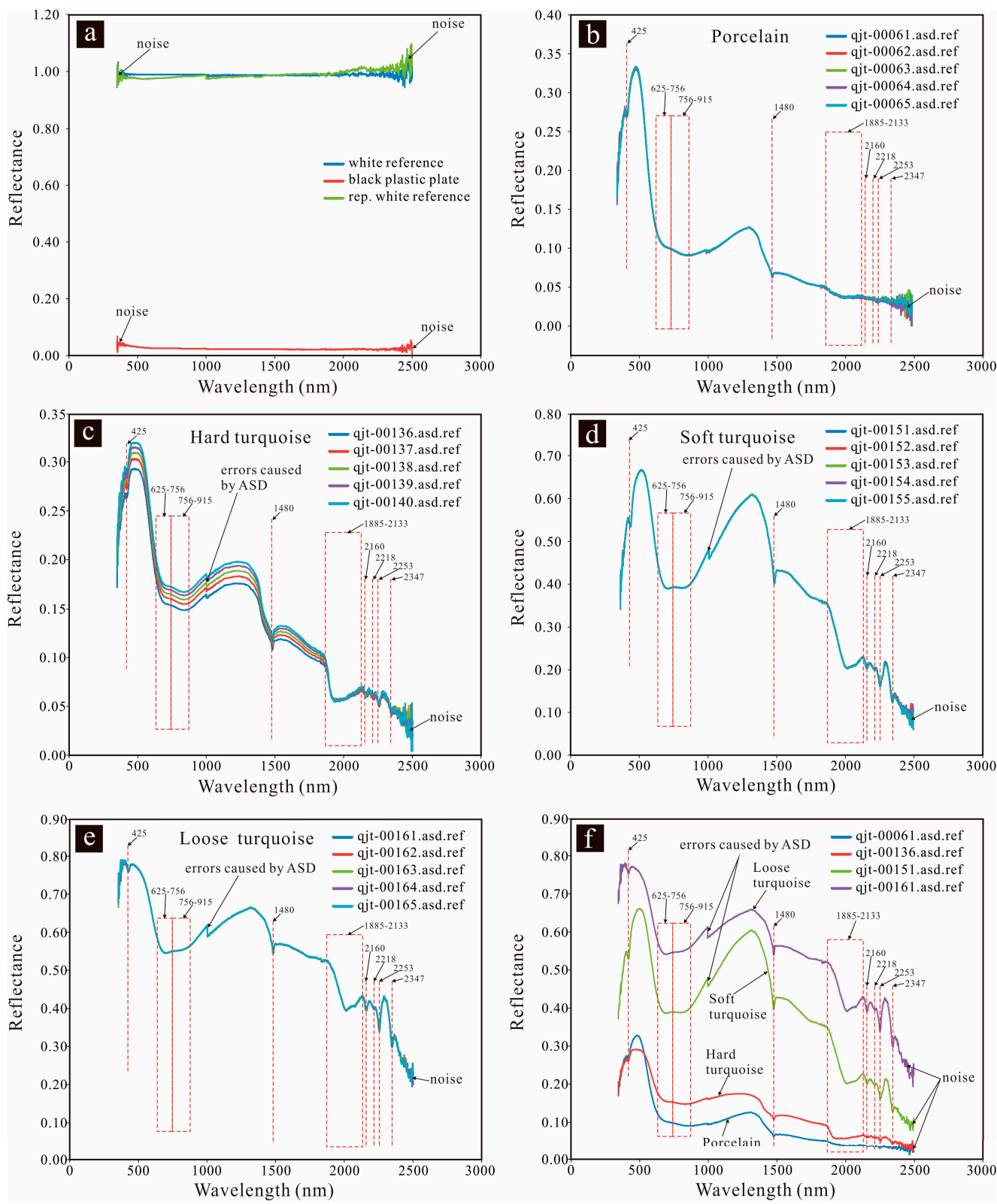

Figure 4. Results of spectral measurements. (a) Spectra for white reference and black plastic plate; (b) Spectra for porcelain (qjt-00061.asd.ref), hard turquoise (qjt-00136.asd.ref), soft turquoise (qjt-00151.asd.ref), and loose turquoise (qjt-00161.asd.ref); (c) Spectra for porcelain (qjt-00061.asd.ref to qjt-00065.asd.ref); (d) Spectra for hard turquoise (qjt-00136.asd.ref to qjt-00140.asd.ref); (e) Spectra for soft turquoise (qjt-00151.asd.ref to qjt-00155.asd.ref); (f) Spectra for loose turquoise (qjt-00161.asd.ref to qjt-00165.asd.ref).

Figure $4 \mathrm{~b}-\mathrm{e}$ display the spectra of four types of turquoise samples. Five spectra were recorded for each sample. The five spectra have the same shape, suggesting that no variation of absorption features 
occurred during the measurement. The abrupt negative shift of the reflectance values at $1000 \mathrm{~nm}$ are not absorption features, but errors caused by different sensors in the ASD ${ }^{\mathrm{TM}}$ TerraSpec spectrometer.

A comparison of the four turquoise samples is shown in Figure 4f. It is clear that all turquoise samples show several absorption features, including six narrow absorption peaks at $425 \mathrm{~nm}, 1480 \mathrm{~nm}$, $2160 \mathrm{~nm}, 2218 \mathrm{~nm}, 2253 \mathrm{~nm}$, and $2347 \mathrm{~nm}$, and three wide peaks between 625-756 nm, 756-915 nm, and 1885-2133 nm. Additionally, it is noted that the strengths of reflectance and absorption increase with decreasing turquoise hardness (Figure 4f). For example, the hardest porcelain sample generally showed the lowest reflectance values and weak absorption features, while the softest loose turquoise sample had the highest reflectance values with apparent absorption features.

\subsection{Hyper-Spectral Image}

The false color composite of the short-wave infrared hyper-spectral image of four types of turquoise samples with typical spectra acquired from the hyper-spectral image are shown in Figure 5. The spectra determined by the HySpex ${ }^{\mathrm{TM}}$ imager are similar to those measured by the ASD ${ }^{\mathrm{TM}}$ spectrometer (Figure 4). Narrow absorption peaks at $1480 \mathrm{~nm}, 2253 \mathrm{~nm}$, and $2347 \mathrm{~nm}$, and a wide peak between 1885 and $2133 \mathrm{~nm}$ were observed, while peaks at $2160 \mathrm{~nm}$ and $2218 \mathrm{~nm}$ were sheltered by signal noise between $2000 \mathrm{~nm}$ and $2500 \mathrm{~nm}$.

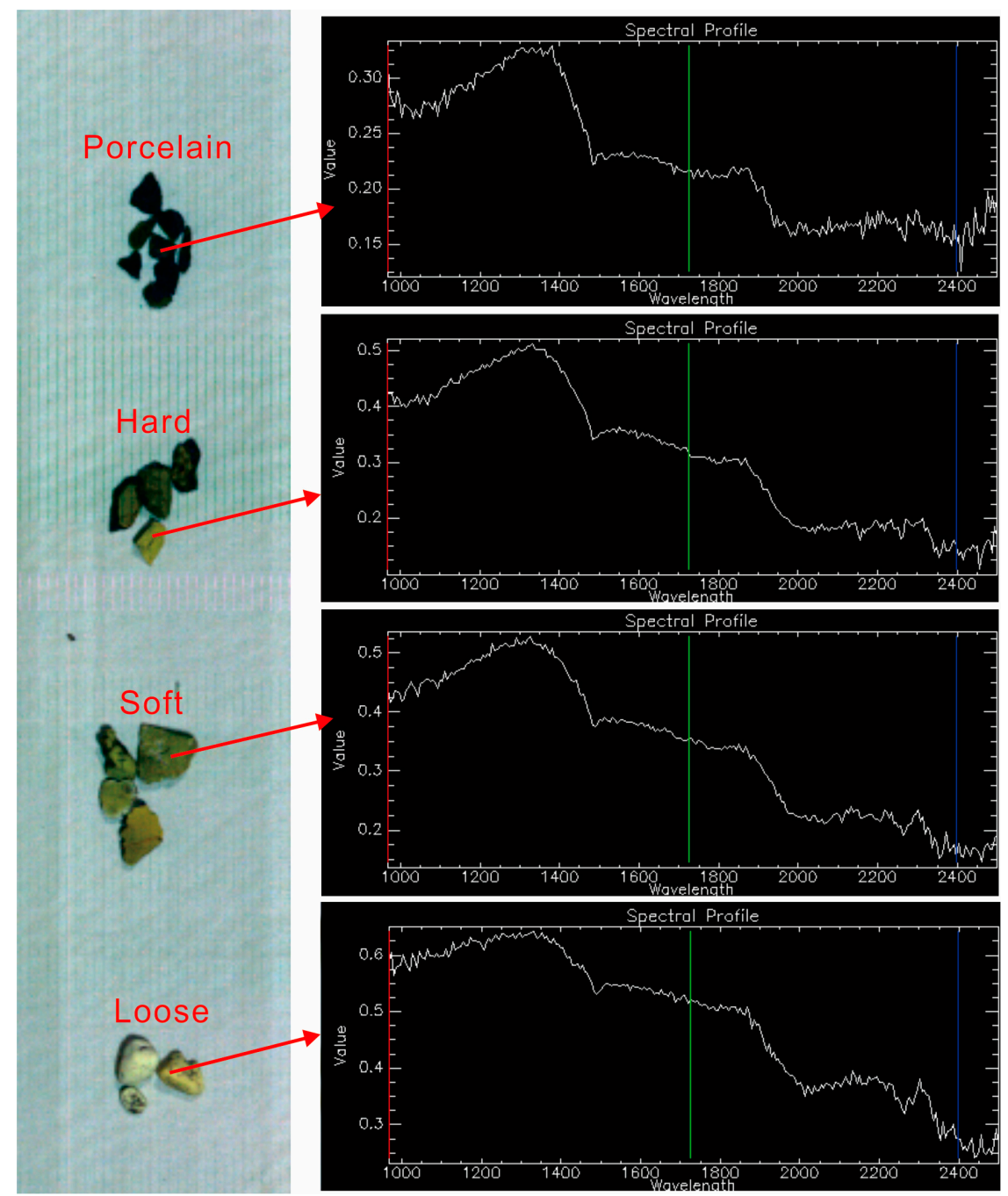

Figure 5. Short-wave infrared hyper-spectral image for four turquoise samples accompanied with reflectance spectra. 


\section{Discussion}

\subsection{Absorption Mechanism}

Although the chemical composition of turquoise has been studied previously [30], and a formula has been proposed for this mineral $\left(\mathrm{Cu}\left(\mathrm{Al}, \mathrm{Fe}^{3+}\right)_{6}\left(\mathrm{PO}_{4}\right)_{4}(\mathrm{OH})_{8} \cdot 4 \mathrm{H}_{2} \mathrm{O}\right)$, the relationships between radicals in the turquoise molecule and absorptions at different wavelengths are still vague.

To investigate the absorption mechanism, we determined the spectra of some chemical compounds, including $\mathrm{NaH}_{2} \mathrm{PO}_{4} \cdot 2 \mathrm{H}_{2} \mathrm{O}, \mathrm{Na}_{4} \mathrm{P}_{2} \mathrm{O}_{7} \cdot 10 \mathrm{H}_{2} \mathrm{O}, \mathrm{FeSO}_{4} \cdot 7 \mathrm{H}_{2} \mathrm{O}, \mathrm{CuSO}_{4} \cdot 5 \mathrm{H}_{2} \mathrm{O}$, and $\mathrm{NaOH}$, and several rock minerals, such as hematite, limonite, illite, kaolinite, muscovite, and montmorillonite. The spectra of the above chemical compounds and minerals are shown in Figure 6 with the spectra of porcelain and loose turquoise.

As displayed in Figure 6, the absorption peaks of turquoise at $2160 \mathrm{~nm}, 2218 \mathrm{~nm}, 2253 \mathrm{~nm}$, and $2347 \mathrm{~nm}$ are also observed on the spectra of clay minerals, such as illite, limonite, kaolinite, muscovite, and montmorillonite. These absorptions are usually related to the vibration of Al-OH [31]. The absorption peak at $425 \mathrm{~nm}$ can be found on the spectrum of $\mathrm{FeSO}_{4} \cdot 7 \mathrm{H}_{2} \mathrm{O}$, and is probably related to ferrous ion. The first two wide peaks between $625 \mathrm{~nm}$ and $756 \mathrm{~nm}$ and between $756 \mathrm{~nm}$ and $915 \mathrm{~nm}$ also exist on the spectra of $\mathrm{CuSO}_{4} \cdot 5 \mathrm{H}_{2} \mathrm{O}$ and hematite, suggesting that they are associated with copper ion and ferric ion, respectively. The third wide peak between $1885 \mathrm{~nm}$ and $2133 \mathrm{~nm}$ occurs in the spectra of $\mathrm{FeSO}_{4} \cdot 7 \mathrm{H}_{2} \mathrm{O}, \mathrm{CuSO}_{4} \cdot 5 \mathrm{H}_{2} \mathrm{O}, \mathrm{NaH}_{2} \mathrm{PO}_{4} \cdot 2 \mathrm{H}_{2} \mathrm{O}$, and limonite, indicating that this peak is related to crystal water. It is interesting that the absorption peak of turquoise at $1480 \mathrm{~nm}$ is identical to that of $\mathrm{Na}_{4} \mathrm{P}_{2} \mathrm{O}_{7} \cdot 10 \mathrm{H}_{2} \mathrm{O}$ and close to the absorption at $1470 \mathrm{~nm}$ of $\mathrm{NaH}_{2} \mathrm{PO}_{4} \cdot 2 \mathrm{H}_{2} \mathrm{O}$, which may be induced by the vibration of $\mathrm{P}-\mathrm{OH}$.

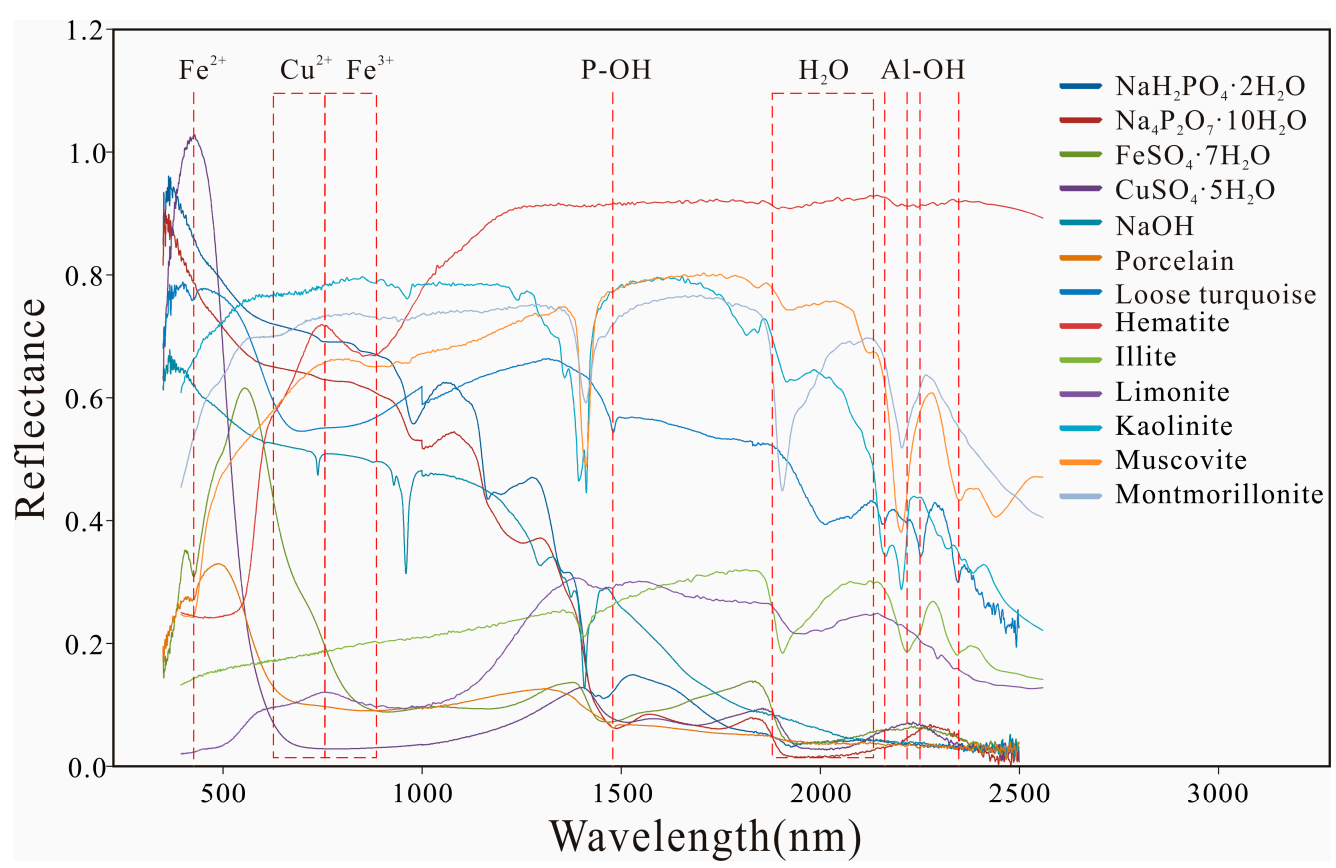

Figure 6. Spectra of several chemical compounds and rock minerals with spectra of porcelain (qjt-00061.asd.ref) and loose turquoise (qjt-00161.asd.ref).

\subsection{Mapping Turquoise Samples Using Hyper-Spectral Image}

Several methods and algorithms to identify minerals based on imaging spectroscopy have been proposed by many previous studies. We take the Spectral Angle Mapper (SAM) method as an example of turquoise identification and mapping using hyper-spectral images. This algorithm calculates the similarity between the image and reference spectra by treating them as vectors in $n$-dimensional space 
and calculating the corresponding angle between them (Equation (1)). With respect to Equation (1), $n_{b}$ is the number of bands, $t_{i}$ is the reflectance of band $i$ of the image spectrum, and $r_{i}$ is the reflectance of band $i$ of the reference spectrum.

$$
\cos \alpha=\frac{\sum_{i=1}^{n b} t_{i} r_{i}}{\sqrt{\sum_{i=1}^{n b} t_{i}^{2}} \sqrt{\sum_{i=1}^{n b} r_{i}^{2}}}
$$

In this study, the computation of the spectral angle was carried out using ENVI 5.0 software. We took the hard turquoise spectrum obtained from the hyper-spectral image as the reference spectrum, and set the maximum spectral angle to 0.165 (rad) to do spectral angle mapping of all turquoise samples. As shown in Figure 7, all turquoise samples were successfully recognized. Additionally, as a great amount of turquoise samples can be rapidly scanned (100 fps) by the imager at one time, the hyper-spectral image may serve as a convenient and fast tool for turquoise identification and selection, especially for batch determination.
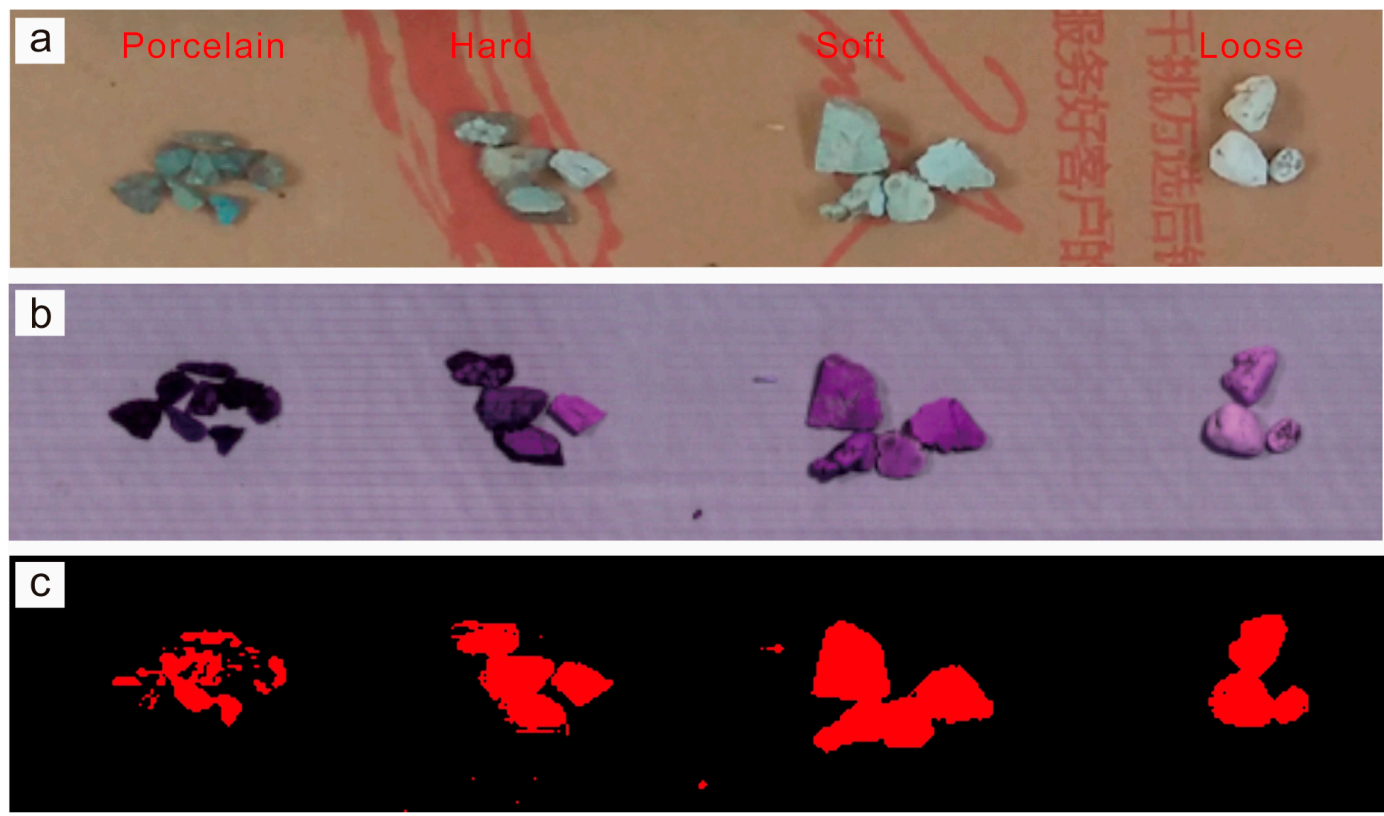

Figure 7. (a) True color composite image of four types of turquoise samples; (b) False color composite of the short-wave infrared hyper-spectral image of four types of turquoise samples; (c) Mapping result for all turquoise samples.

\section{Conclusions}

1. The reflectance characteristics of four types of turquoise samples, including porcelain, hard, soft, and loose turquoises were investigated using an $\mathrm{ASD}^{\mathrm{TM}}$ spectrometer. Six narrow absorption peaks at $425 \mathrm{~nm}, 1480 \mathrm{~nm}, 2160 \mathrm{~nm}, 2218 \mathrm{~nm}, 2253 \mathrm{~nm}$, and $2347 \mathrm{~nm}$, and three wide peaks between 625-756 nm, 756-915 nm, and 1885-2133 nm were observed. The reflectance and absorption intensities of turquoise increase with decreasing hardness.

2. Comparison among absorption features of chemical compounds, rock minerals, and turquoise suggests that the absorption features of turquoise are probably related to $\mathrm{Al}-\mathrm{OH}, \mathrm{P}-\mathrm{OH}$, ferrous ion, ferric ion, copper ion, and crystal water.

3. Turquoise samples in the hyper-spectral image were successfully recognized using spectral angle mapper, suggesting that hyper-spectral image may be used for convenient and rapid turquoise identification and selection. 
Acknowledgments: This study was financially supported by National Natural Foundation of China (Nos. 41502037 and 41601008) and the Youth Foundation of Beijing Research Institute of Uranium Geology (Nos. DD1405-A and YQJ1601). Thanks are also due to the editors for their editorial handing and anonymous reviewers for their comments and suggestions.

Author Contributions: Jun-Ting Qiu measured reflectance spectra and wrote the experiment part. Hui Qi provided the turquoise samples and wrote the sample description part. The introduction part was written by Jun-Ting Qiu and Hui Qi. The result, discussion, and conclusion parts were written by Jun-Ting Qiu, and modified by Ji-Lin Duan. The experiment procedure were recorded and photographed by Hui Qi, and monitored by Ji-Lin Duan.

Conflicts of Interest: The authors declare no conflict of interest.

\section{References}

1. Cloutis, E.A. Hyperspectral geological remote sensing: Evaluation of analytical techniques. Int. J. Remote Sens. 1996, 17, 2215-2242. [CrossRef]

2. Dwivedi, R.S. Soil resources mapping: A remote sensing perspective. Remote Sens. Rev. 2001, 20, 89-122. [CrossRef]

3. Slonecker, E.T.; Jennings, D.B.; Garofalo, D. Remote sensing of impervious surfaces: A review. Remote Sens. Rev. 2001, 20, 227-255. [CrossRef]

4. Maathuis, B.H.P.; van Genderen, J.L. A review of satellite and airborne sensors for remote sensing based detection of minefields and landmines. Int. J. Remote Sens. 2004, 25, 5201-5245. [CrossRef]

5. Congalton, R.G. Remote Sensing: An Overview. GISci. Remote Sens. 2010, 47, 443-459. [CrossRef]

6. Ghiyamat, A.; Shafri, H.Z.M. A review on hyperspectral remote sensing for homogeneous and heterogeneous forest biodiversity assessment. Int. J. Remote Sens. 2010, 31, 1837-1856. [CrossRef]

7. Dietz, A.J.; Kuenzer, C.; Gessner, U.; Dech, S. Remote sensing of snow-A review of available methods. Int. J. Remote Sens. 2012, 33, 4094-4134. [CrossRef]

8. Chabrillat, S.; Pinet, P.C.; Ceuleneer, G.; Johnson, P.E.; Mustard, J.F. Ronda peridotite massif: Methodology for its geological mapping and lithological discrimination from airborne hyperspectral data. Int. J. Remote Sens. 2000, 21, 2363-2388. [CrossRef]

9. Chen, Q.; Yin, Z.; Qi, L.; Xiong, Y. Turquoise from Zhushan county, Hubei province, China. Gems Gemol. 2012, 48, 198-204. [CrossRef]

10. Harris, J.R.; McGregor, R.; Budkewitsch, P. Geological analysis of hyperspectral data over southwest Baffin Island: Methods for producing spectral maps that relate to variations in surface lithologies. Can. J. Remote Sens. 2010, 36, 412-435. [CrossRef]

11. Slavinski, H.; Morris, B.; Ugalde, H.; Spicer, B.; Skulski, T.; Rogers, N. Integration of lithological, geophysical, and remote sensing information: A basis for remote predictive geological mapping of the Baie Verte Peninsula, Newfoundland. Can. J. Remote Sens. 2010, 36, 99-118. [CrossRef]

12. Babu, P.S.; Majumdar, T.J.; Bhattacharya, A.K. Study of spectral signatures for exploration of Bauxite ore deposits in Panchpatmali, India. Geocarto Int. 2015, 30, 545-559. [CrossRef]

13. Boesche, N.K.; Rogass, C.; Lubitz, C.; Brell, M.; Herrmann, S.; Mielke, C.; Tonn, S.; Appelt, O.; Altenberger, U.; Kaufmann, H. Hyperspectral REE (Rare Earth Element) Mapping of Outcrops-Applications for Neodymium Detection. Remote Sens. 2015, 7, 5160-5186. [CrossRef]

14. Qiu, J.-T.; Zhang, C.; Hu, X. Integration of Concentration-Area Fractal Modeling and Spectral Angle Mapper for Ferric Iron Alteration Mapping and Uranium Exploration in the Xiemisitan Area, NW China. Remote Sens. 2015, 7, 13878-13894. [CrossRef]

15. Zhang, B.; Wu, D.; Zhang, L.; Jiao, Q.; Li, Q. Application of hyperspectral remote sensing for environment monitoring in mining areas. Environ. Earth Sci. 2012, 65, 649-658. [CrossRef]

16. Lugassi, R.; Chudnovsky, A.; Zaady, E.; Dvash, L.; Goldshleger, N. Estimating Pasture Quality of Fresh Vegetation Based on Spectral Slope of Mixed Data of Dry and Fresh Vegetation-Method Development. Remote Sens. 2015, 7, 8045-8066. [CrossRef]

17. Pas, I.; Rodrigues, A.; Gonalves, S.; Costa, P.M.; Gonalves, I.; Pereira, L.S.; Cunha, M. Predicting Grapevine Water Status Based on Hyperspectral Reflectance Vegetation Indices. Remote Sens. 2015, 7, 16460-16479. 
18. Qiu, J.-T.; Li, P.-J.; Yu, Z.-F.; Li, P. Petrology and Spectroscopy Studies on Danxia Geoheritage in Southeast Sichuan Area, China: Implications for Danxia Surveying and Monitoring. Geoheritage 2015, 7, 307-318. [CrossRef]

19. Dale, L.M.; Thewis, A.; Boudry, C.; Rotar, I.; Dardenne, P.; Baeten, V.; Pierna, J.A.F. Hyperspectral Imaging Applications in Agriculture and Agro-Food Product Quality and Safety Control: A Review. Appl. Spectrosc. Rev. 2013, 48, 142-159. [CrossRef]

20. Kandpal, L.M.; Lee, H.; Kim, M.S.; Mo, C.; Cho, B.-K. Hyperspectral Reflectance Imaging Technique for Visualization of Moisture Distribution in Cooked Chicken Breast. Sensors 2013, 13, 13289-13300. [CrossRef] [PubMed]

21. Attasa, M.; Cloutis, E.; Collins, C.; Goltz, D.; Majzels, C.; Mansfield, J.R.; Mantsch, H.H. Near-infrared spectroscopic imaging in art conservation: Investigation of drawing constituents. J. Cult. Herit. 2003, 4, 127-136. [CrossRef]

22. Cavalli, R.M.; Colosi, F.; Palombo, A.; Pignatti, S.; Poscolieri, M. Remote hyperspectral imagery as a support to archaeological prospection. J. Cult. Herit. 2007, 8, 272-283. [CrossRef]

23. Goltz, D.; Attas, M.; Young, G.; Cloutis, E.; Bedynski, M. Assessing stains on historical documents using hyperspectral imaging. J. Cult. Herit. 2010, 11, 19-26. [CrossRef]

24. Wang, F. A Gemological Study of Turquoise in China. Gems Gemol. 1986, 22, 35-37.

25. Fritsch, E.; McClure, S.F.; Ostrooumov, M.; Andres, Y.; Moses, T.; Koivula, J.I.; Kammerling, R.C. The Identification of Zachery-Treated Turquoise. Gems Gemol. 1999, 35, 4-16. [CrossRef]

26. Choudhary, G. A New Type of Composite Turquoise. Gems Gemol. 2010, 46, 106-113. [CrossRef]

27. Choudhary, G.; Gem Testing Laboratory. Turquoise-Rock Crystal Composite. Gems Gemol. 2013, 49, 2.

28. Han, W.; Lu, T.; Dai, H.; Su, J.; Dai, H. Impregnated and Dyed Turquoise. Gems Gemol. 2015, 51, 3.

29. HySpex Cameras. Available online: http://www.hyspex.no/products/disc/swir-320m-e.php (accessed on 26 December 2016).

30. Chen, X.; Warner, T.A.; Campagna, D.J. Integrating visible, near-infrared and short-wave infrared hyperspectral and multispectral thermal imagery for geological mapping at Cuprite, Nevada: A rule-based system. Int. J. Remote Sens. 2010, 31, 1733-1752. [CrossRef]

31. Clark, R.N.; Swayze, G.A.; Wise, R.; Livo, K.E.; Hoefen, T.M.; Kokaly, R.F.; Sutley, S.J. USGS Digital Spectral Library Splib05a; USGS Open File Report 03-395; U.S. Geological Survey: Reston, VA, USA, 2003.

(C) 2016 by the authors; licensee MDPI, Basel, Switzerland. This article is an open access article distributed under the terms and conditions of the Creative Commons Attribution (CC-BY) license (http://creativecommons.org/licenses/by/4.0/). 